\title{
On the energy required to maintain an ocean mirror using the reflectance of foam.
}

\author{
Eduardo Garciadiego Ortega, Julian R.G.Evans ${ }^{a}$ \\ Department of Chemistry, \\ University College London, \\ 20 Gordon Street, \\ London. WC1H OAJ, UK
}

\begin{abstract}
Among the various interventions proposed to remediate the health and security effects of climate change by solar radiation protection is the proposal to enhance natural ocean whitecap formation. Compared to other solar protection interventions, this is technically simple and quickly terminated. However it has a drawback: even if the energy be obtained from wind or wave, the power demand to maintain a foam raft determines the capitalization of equipment. The average power demand is inversely related to foam lifetime which can be prolonged by surfactants preferably derived from ingenerate resources. Here we estimate the associated energy and power demands by identifying the parameters that can be adjusted to moderate the capital cost of implementation. Before dividing by efficiency factors, the range of power demand for an intermediate areal energy requirement of 5 $\mathrm{MJ} / \mathrm{km}^{2}$ of ocean varies from 6 to $30 \mathrm{~W} / \mathrm{km}^{2}$ for foam lifetime of 10 to 2 days. The most likely route to deployment is through merchant ship lubrication using bubbly liquids which both reduces fuel consumption and creates an extended wake and is perhaps an example of technical symbiosis.
\end{abstract}

Keywords: albedo, climate restoration, ocean foam, reflectance

\footnotetext{
a Author to whom correspondence should be addressed:j.r.g.evans@ucl.ac.uk
} 


\section{Introduction}

The health management challenges of climate change have been clearly identified as arising from water stress, food shortage, large scale population migration, shelter and human settlement, extreme weather events and changes to morbidity caused, for example, by disease vector migration $[1,2]$. There are identifiable security threats [3], US Homeland Security concerns [4] and historical evidence that climate change is associated with political instability [5]. Attempts to mitigate anthropogenic climate change by the three principal interventions of (i) reduction in fossil fuel consumption, (ii) switching to non-fossil fuel energy sources and (iii) capture of $\mathrm{CO}_{2}$ and storage in geological cavities suffer from long implementation timescales often linked to replacement rates. Moreno-Cruz and Keith [6] propose, in a decision-making model, that the reduction of solar radiation is viable largely because of its comparative speed of implementation. It does not address the cause of climate change: indeed it remediates global warming whatever the cause.

This fourth class of intervention, to increase the earth's albedo has appeared somewhat uncomfortably under the designation 'geoengineering' or better 'climate remediation' or 'global protection'. Public perception of 'geoengineering' is, on the one hand, not well informed [7] and on the other, surprisingly accepting of a need for some way to manage climate change [8]. The designation 'geoengineering' can be defined as "intentional large-scale manipulation of the environment" [9]. The combustion of fossil fuels which has been known, since the beginning of the $20^{\text {th }}$ century, from a series of papers by Arrhenius 1896 to 1906 [10], to modify the climate on a large scale is not generally described as geoengineering although it is of course, now conducted in scientia.

Budyko [11] made one of the first suggestions to reflect solar radiation by injecting particles into the stratosphere. This idea was reinforced by Nobel laureate Paul Crutzen [12]. Concern over the reintroduction of a 'pollutant' and the uncertain atmospheric chemistry has prompted the quest for 'softer' climate remediation measures. The particulate residence time of 2-3 years which could envelope a major volcanic event and in combination, introduce catastrophic cooling prompts a search for interventions that can be attenuated within a few Ms.

A focus for these is the ocean which occupies $71 \%$ of the earth's surface and has a low reflectance of $\sim 0.04$. British and American scientists have suggested the use of ocean bubbles to increase albedo [13,14]. Ocean whitecaps provide reflectance of 40-60\% [15] depending on the number of bubble rafts $[16,17]$ and finer surfactant foams can produce slightly higher reflectance [17]. Whitecap coverage is related to the $10 \mathrm{~m}$ wind speed [18] but to reach an area fraction of $1 \%$ requires Beaufort 9-10 (severe gale to storm) conditions. It is already known that the ocean bubbles produced by ship wakes increase ocean albedo and influence the radiation balance [19,20]. Recent 
attempts have been made to secure longer seawater foam lifetime by combining additives at the $1 \%$ level which cause gelation [21] and in this way blends of protein and pectin or methyl cellulose and carrageenan provide exceptionally long lifetimes in the laboratory without wave action. Seasalt crystallisation at the upper surfaces of the foam as it dries tends to increase reflectance [22]. Computer modelling suggests that 'ocean brightening' has fewer side effects than other remediations when the coverage is reasonably uniform [23]. Simulation also suggests that ocean foams placed in arctic waters (where solar zenith angle is unfavourably high) would cease to be effective in restoring ice cover once Arctic annual mean temperature has risen by $10{ }^{\circ} \mathrm{C}$ above preindustrial conditions even though the foam provides similar albedo to ice itself [24]. Clearly deployment of foam rafts in lower latitudes with lower solar zenith angle would continue to provide global cooling as indicated by Gordon and Jacobs [25] in their 1977 study of the effects of sea foam on albedo. Time is therefore of the essence and possibly one of the greatest dangers is the precipitate implementation of global protection climate engineering measures under political pressure in a humanitarian effort to prevent suffering but long before the prerequisite research has been completed; a politico-scientific scenario that could have serious consequences.

\section{Overview of the problem}

The overall aim is to evaluate the viability of using large areas of foam in the ocean to reflect sunlight in terms of criteria proposed in the Royal Society report [26] and our analysis approaches this goal in part by addressing the energy demand. A comparable but more recent survey published by the National Academy of Sciences [27] dismisses the use of ocean foams as "judged to be of low potential use on the global scale because of generally low effectiveness and high costs" but adds the contrary statement; "There is very little published research on this idea". Thus "effectiveness" is judged by the impact on the Earth's energy budget: an ocean foam requires high reflectance (0.50.6) and persistence. For comparison, sea ice has a reflectance of 0.5-0.8 and in the laboratory, foams can have reflectance approaching 0.8. "Affordability” is judged by the capitalization and running costs of foam engineering equipment. The energy to produce and sustain a large area of foam in the ocean will ideally be harvested from renewable sources so the main issue is capitalization but a potential solution has been found (vide infra). "Timeliness" is assessed by the timescales for implementation and termination. Since conventional engineering equipment is likely to be deployed, implementation should be short in comparison to other climate remediation strategies. Termination is fixed by foam lifetime. In terms of assessment of "safety" the wider issue of regional climate effects is beyond the scope of this work but is being pioneered by the Leeds team [23]. There are questions about the restriction of sunlight to the ocean biosphere and to gas 
transfer in the boundary region which are likely to be similar to the restrictions imposed by ice and will depend partly on the uniformity of cover. It is noteworthy that surfactant additions can suppress air-sea gas exchange [28]. Regions known as "ocean deserts" or the high-nutrient, low-chlorophyll regions which support reduced marine life and are growing in extent [29] occupy some $50 \times 10^{6} \mathrm{~km}^{2}$ of ocean and may become locations for initial deployment of an ocean mirror. The local issue of safety of foam agents will depend on the materials selected; the idea of using ingenerate resources such as phytoplankton mucilage and derivatives of seaweed go some way to ameliorate these concerns and biodegradability will be required. Nevertheless, the desire for global protection from the predicted consequences of climate change at zero monetary or environmental cost is likely to result in disappointment and a difficult balance will need to be found.

Although the energy to create and sustain an ocean mirror using foam could be drawn from the renewable sources of wave, wind or solar, the amount of energy so required determines the capitalisation of ocean going vessels and their energy harvesting equipment. Since the area of ocean that is likely to be treated is several percent $\left(1 \%\right.$ represents $\left.3.6 \times 10^{6} \mathrm{~km}^{2}\right)$, this is a substantial amount of equipment. The power required to maintain a given area of foam is inversely related to foam lifetime. It is for this reason that our current efforts are directed to enhancing the longevity of foam $[21,22]$.

Methods of generating foam in sea water include (i) the direct injection of air, (ii) the mechanical stirring of the surface, such as may be obtained from a propeller, (iii) the pumping of sea water and (iv) the bubble lubrication of merchant shipping. There is increasing interest in the Mitsubishi ship lubrication system [30] in which compressed air is discharged under the hull to deliver a low viscosity boundary layer of bubbly liquid thus reducing the consumption of bunker fuel, potentially leaving an extended wake and perhaps providing an example of engineering symbiosis. Estimates suggest that 10-20\% fuel savings are possible [30]. For fuel reduction, small bubbles are not necessary but modification of the system to incorporate turbulence and surfactant addition could provide a long-lasting wake comprised of finer bubbles.

\section{Energy demand in terms of reflectance}

While there are several methods to calculate the reflectance of foams exactly, Edward Monahan, whose career was devoted to the study of ocean whitecaps [16], suggested that the horizontal surfaces made the main contribution to overall reflectance. This considerably simplifies the relation between energy demand and reflectance. Summed to infinity, the method gives reflectance of thick foams consistent with whitecaps [16] and has been tested for lower numbers of 
reflective layers [17]. This simplification may break down for very fine cell foams but it assists in the estimation considerably.

The number of reflective membranes through which the light passes is simply the number of foam rafts $N$ found from overall foam thickness, $h$, and diameter of cells, $d$ :

$$
N=h / d
$$

The series for the first and third reflections (the second and fourth continue in the direction of incident light, and the higher orders contribute less) [17] provides $R_{N}$, the sum of reflections from $N$ membranes where $r$ is the reflectivity of a membrane and includes reflection from both surfaces and $\mathrm{m}=\mathrm{n}-1$ :

$$
R_{N}=r \sum_{n=1}^{n=N}(1-r)^{2(n-1)}+r^{3} \sum_{m=0}^{m=N-1} \frac{m(m+1)}{2}(1-r)^{2 m}
$$

Selecting $R_{N}=0.5$ as the minimum reflectance specification, Table 1 provides the minimum number of membranes which is effectively the minimum number foam rafts to deliver the specification for a given value of $r$, the reflectivity of the membrane (which includes both surfaces) and the corresponding value of $R_{\infty}$, the reflectance for an infinitely thick foam. It also gives the number of rafts to deliver $90 \%$ of the reflectance of the infinitely thick foam.

\begin{tabular}{|c|c|c|c|}
\hline $\begin{array}{c}\text { Reflectivity } \\
\text { of } \\
\text { membrane }\end{array}$ & $\begin{array}{c}\mathrm{R}_{\infty} \\
(\mathrm{N} \rightarrow \infty)\end{array}$ & $\mathrm{N}_{0.5}$ & $\mathrm{~N}_{(0.9 \mathrm{R} \infty)}$ \\
\hline 0.08 & 0.63 & 13 & 19 \\
0.10 & 0.64 & 10 & 15 \\
0.12 & 0.65 & 8 & 13 \\
0.15 & 0.65 & 7 & 10 \\
\hline
\end{tabular}

Table 1. Effect of reflectivity of membrane, $r$, on reflectance of foam. $R_{\infty}$ : reflectance of infinitely thick foam,; $N_{0.5}$ : number of rafts to give $\left.R=0.5 ; N_{(0.9} R \infty\right)$ :number of rafts to give $90 \%$ of $R_{\infty}$.

The reflectivity for the membrane is $\sim 0.1$ as estimated in reference [17] but Table 1 shows that if this varies, which of course it can do as a result, for example, of surfactant addition or entrainment of biological residues, the value of $R_{\infty}$ does not vary greatly although the number of 
rafts needed for $50 \%$ albedo increases as the reflectivity of the layer decreases. The specification of $R=0.5$ is arbitrary but reasonable in that it represents a factor of $\mathrm{x} 10$ improvement on the ocean average albedo. Laboratory foams can be as high as $R=0.77$.

Clearly the foam reflectance declines as the foam decays and for $r=0.1$, the number of layers to obtain $R=0.6$ is 20 and for $R=0.4$ is 8 . So to allow for decay, 20 layers is used for the calculations in subsequent sections. It is assumed that geometric optics can be applied if the wavelength of light is small compared to the object with which it interacts. For $\mathrm{d}<2000 \mathrm{~nm}$, diffraction and scattering effects occur. As bubble size decreases, Stokes' law predicts longer ascent times and therefore longer residence time irrespective of surfactant effects. In the work of Johnson and Cooke [31,32] such bubbles scavenge organic surfactants from the ocean which stabilizes them but a high number density of microbubbles may deplete such naturally occurring surfactants. The approach in this work is to consider macro-bubble foams stabilised by deliberately added, but preferably oceansourced surfactants.

Figure 1 shows graphically how reflectance of the foam develops as the number of rafts increases using this simplified model [17]. As the number of bubble rafts increases, the overall reflectance becomes less sensitive to the membrane reflectivity and $R_{\infty}$ tends to be in the $50-60 \%$ region for each in this region of membrane reflectivity of $\sim 0.1$.

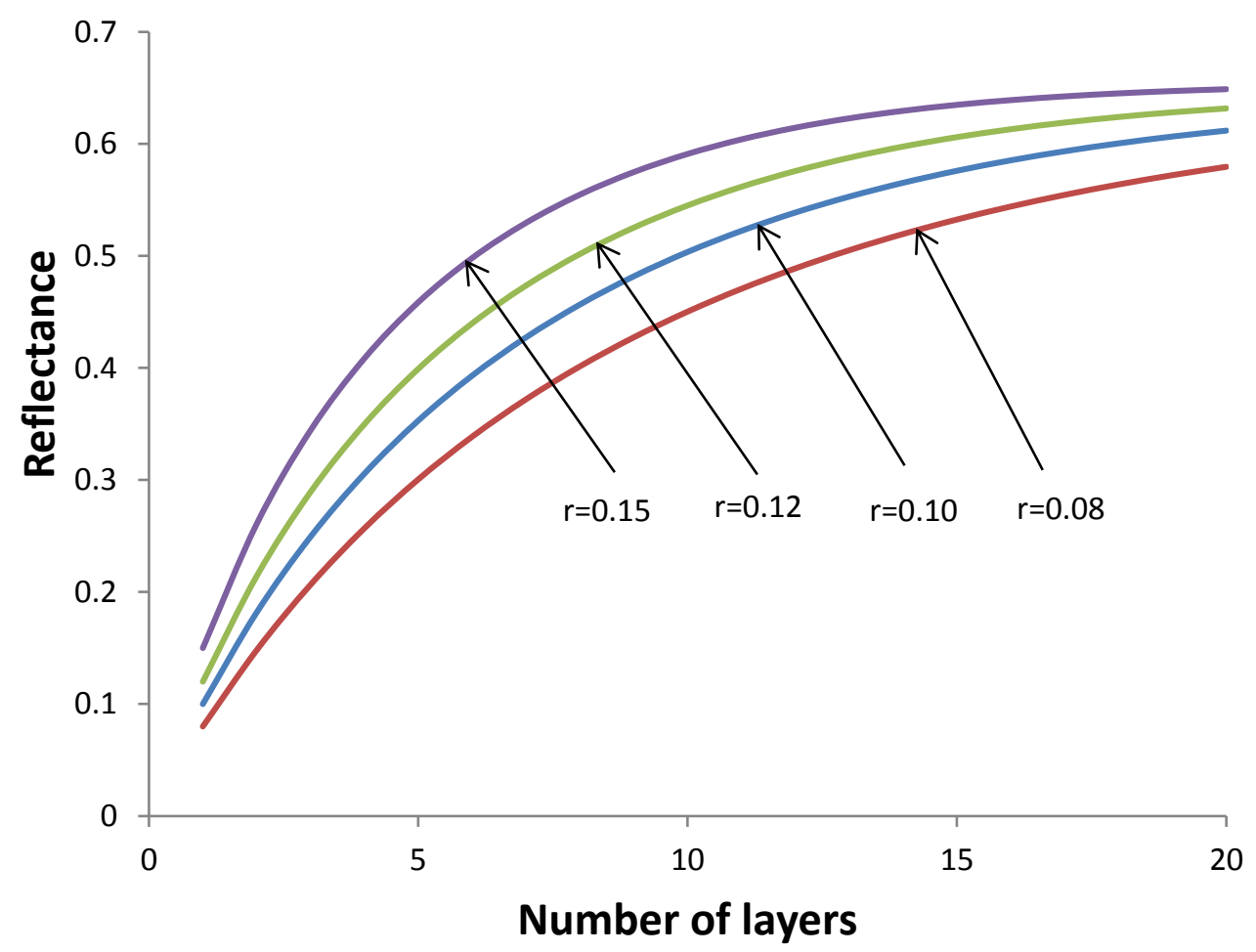


Figure 1. Reflectance contributed by first and third reflections from a foam as a function of the number of layers and the reflectivity, $\mathrm{r}$ of each layer from $\mathrm{r}=0.08-0.15$.

From a thermodynamic approach, the energy invested in the production of $1 \mathrm{~m}^{2}$ of ocean covered with foam must provide the new interfacial area and the increased gas pressure of air entrapped in the bubbles. The energy so calculated for the most efficient process that could be devised would require quasi-static, reversible steps with no inefficiencies or viscous losses. The actual energy required may then be found with the use of efficiency factors.

The initial state is defined as the aqueous solution and air at a reference temperature and at atmospheric pressure. The initial interfacial surface area is negligible compared to that of the foam. The transient state is defined as foam with a precise amount of interfacial surface and the pressure is above atmospheric pressure being dependant on the foam cell size and calculated via the YoungLaplace equation. The final temperature is the same as the initial temperature but an adiabatic compression is considered to take place with subsequent heat dissipation.

Figure 2 shows schematically the foam energy evolution over time. The initial and final states are the same because foam is an unstable system that will eventually degrade. The energy of the initial foam is exactly the same as the thermodynamic work applied to the system. The practical work is obtained, as discussed above, by dividing the thermodynamic work by an efficiency factor $\eta$ $(0<\eta<1)$. With the consideration of adiabatic compression but isothermal foam, a heat dissipation step is included. The path taken from the initial foam which consists of spherical bubbles in water to polyhedral foam is distinguished schematically in Figure 2 by an exaggerated change in slope of the decay curve. The subsequent decay to the final point is dependent on the foam degradation processes. These irreversible, spontaneous processes such as coarsening and film rupture do not have to be considered in this evaluation since all the calculations are pathindependent. Throughout the analysis, the geometric area of ocean is considered (flat ocean) so that a roughness factor can be introduced subsequently. Complete entrainment of the pumped air is considered. These factors can be introduced into the model as it approaches the real case. 


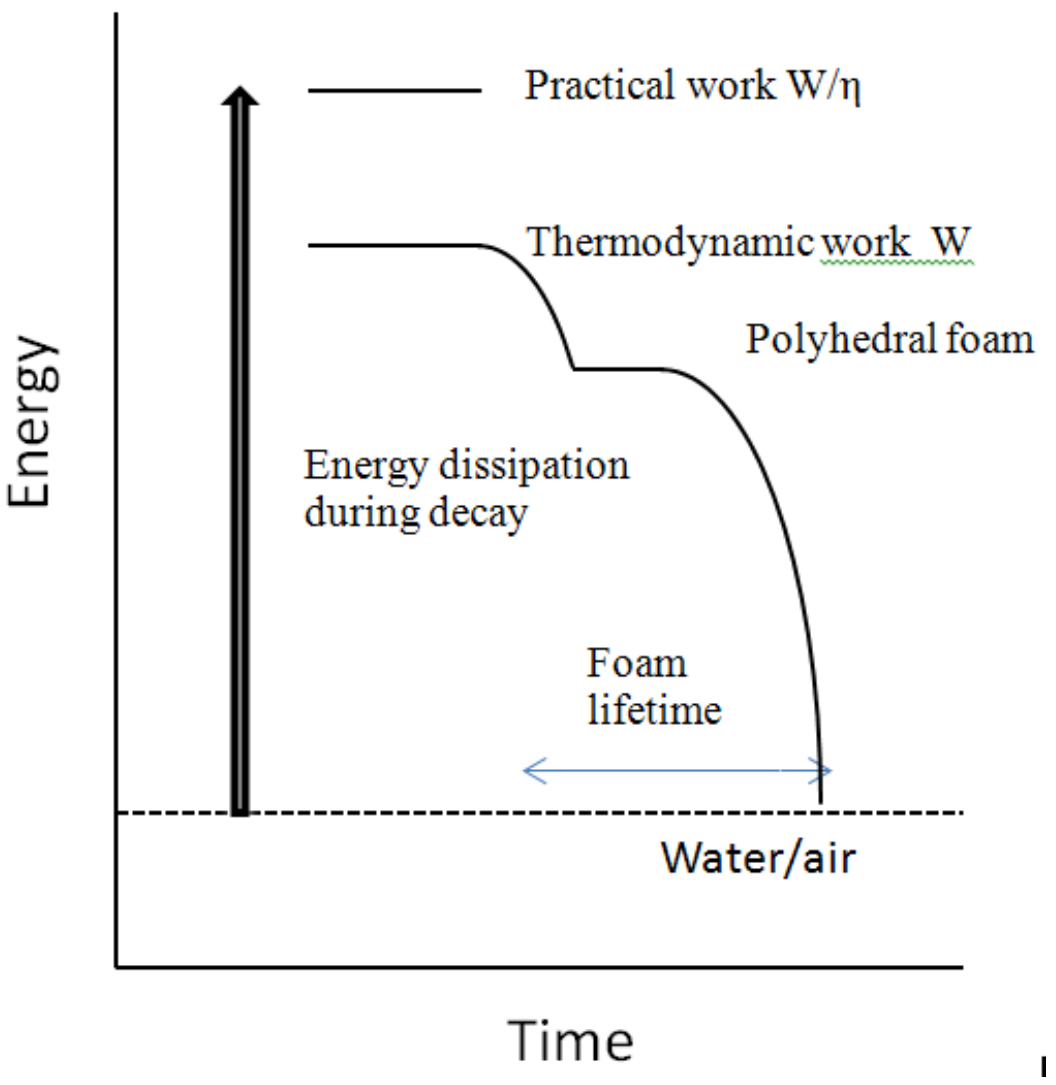

Figure 2. Schematic diagram of energy changes during manufacture and decay of the ocean foam. The initial work done $\mathrm{W} / \eta$ represents the total work input where $\eta$ is the overall efficiency, $\mathrm{W}$ is the work done in creating spherical bubbles, which decay in two steps, (i) to a polyhedral foam and (ii) by coalescence and collapse to the minimum sea-water interface.

The thermodynamic work to produce foam is the sum of work of compression, $W_{c}$ and the interfacial surface energy $W_{S}$ :

$$
W_{\mathrm{T}}=W_{C}+W_{S}
$$

Estimation of $\mathrm{W}_{\mathrm{S}}$ requires the foam geometry for the total area of film contained in unit foam volume. For Monahan's cubic foam [16] aligned with faces parallel to the ocean surface and with cell dimension $d$ ( $\mathrm{d}$ is side length), the surface area/volume of a cube is $6 / \mathrm{d}$ and the volume of the foam is $\mathrm{h}$ per $\mathrm{m}^{2}$ of ocean so the surface energy per unit area of ocean $=6 \sigma \mathrm{N}$. Thus for $\mathrm{N}=20, \sigma=$ $0.04 \mathrm{Jm}^{-2}$ giving initial reflectance of 0.6 , the surface energy per unit ocean area is $4.8 \mathrm{Jm}^{-2}$. 
For 3-D polyhedral foams, the average coordination number, $z$, was derived by Kelvin, subsequently revisited by Weaire and Phelan [33] and most recently Gabbrielli [34] to be 14, 13.5 and 13.7 respectively. These coordination numbers approximate to a tetrakaidecahedron, the spacefilling structure for which $z=14$. In a study of similar structures in plants, the volume of a tetrakaidecahedron, $v_{T}=2.34 c^{3}$ where $\mathrm{c}$ is the mean chord length as measured by an intercept method [35]. This is the distance between the intercepts made by any random straight line drawn through the structure and the cell boundaries and since the straight line is the path of a light ray, $\mathrm{c}$ is thus the average distance between successive membranes for the purpose of calculating reflectance. The average cell diameter $d=c / 0.616$ [36] and for a tetrakaidecahedron, the average caliper diameter is $3 L$ where $L$ is the side length [37]. The surface area per unit volume is $2.37 / L$ [38] and since diameter $=3 L$, surface area per unit volume is $7.11 / d$ slightly higher than the corresponding surface to volume ratio for a sphere of $6 / d$ ( $d$ is diameter in both cases). Since we require $N=20$ membranes in the foam layer, it is $h / c$ that is put at 20 rather than $h / d$ because the chord length is derived from intercepts along the path of a ray. Thus $N=h / 0.616 d$ and $h / d=12.32$. The surface energy per unit ocean area is thus $4.38 \sigma N$ which for $\sigma=0.04 \mathrm{Jm}^{-2}$ gives $3.5 \mathrm{Jm}^{-2}$ of ocean.

The surface energy of distilled water is $0.072 \mathrm{~J} \mathrm{~m}^{-2}$ at $20{ }^{\circ} \mathrm{C}$ and of abiotic sea water typically 0.073-0.075 $\mathrm{J} \mathrm{m}^{-2}$ [39]. However it is lowered considerably by surfactants: ideally ocean-sourced or biosourced surfactants are preferred to achieve persistent foams. The stored surface energy depends linearly on the value of the specific surface energy and although this can be rendered low by surfactants, there is a practical lower limit and a range for surface energy of $0.02<\sigma<0.06 \mathrm{~J} \mathrm{~m}^{-2}$ was used.

$$
W_{s}=4.38 \sigma N
$$

$W_{s}$ is here the energy (or work) required to produce the surface area per unit ocean area of foam. For an initial reflectance of $0.6(N=20), W_{s}=87.6 \sigma$ which, for the range of surface energy explored is between 1.8 and $5.3 \mathrm{Jm}^{-2}$ of ocean surface. The bubble size is subsumed in $N$.

To calculate the compression contribution $W_{c}$, the first step is to calculate the pressure inside the foam $P_{2}$, The Young-Laplace equation for spherical bubbles in a liquid is:

$$
P_{2}=P_{1}+\frac{4 \sigma}{d}
$$

where $\mathrm{P}_{1}$ is the atmospheric pressure. We are here concerned with the compression work to obtain the initial wet foam, that is, spherical bubbles in a liquid rather than the polyhedral foam that develops from it (Figure 1). By allowing for the widest range of diameters from $0.002 \mathrm{~mm}$ up to $1 \mathrm{~mm}$, 
(thereafter the pressure increase is very low) it is possible to show how the energy demand varies from high levels needed to produce microbubbles through to relatively low values for millimetre sized cells. The pressure demand is plotted in Figure 3 where the ratio $\mathrm{P}_{2} / \mathrm{P}_{1}$ is calculated as a function of the diameter, whose axis is logarithmic, for three surface energy values.

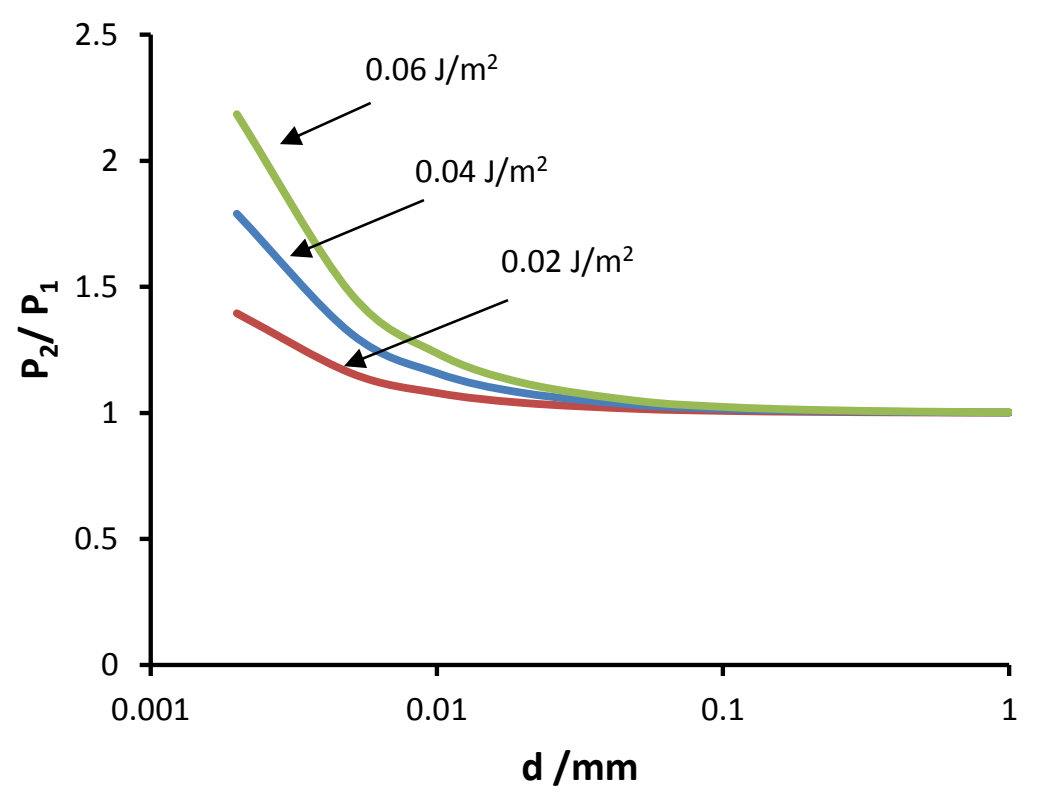

Figure 3. Ratio of pressure inside a spherical bubble, $P_{2}$ to atmospheric pressure, $P_{1}$ as a function of diameter for three representative values of surface energy.

There are several technical means to create a foam but here we consider the use of compressed air to inject bubbles. We require the work done by a compressor in an adiabatic, reversible process to compress a gas from atmospheric $P_{1}$ to a higher pressure, in this case $P_{2}$, which is given by Equation 6. $W_{C} / V_{2}$ is the compression work divided by the volume of air at $P_{2}$, that is, the volume of gas in the foam and $\gamma$ is the specific heat ratio $C_{P} / C_{V}$. For air and diatomic gases at moderate temperatures, $\gamma \sim$ 1.4. Figure 4 is the log-log plot of Equation 6 with the same range of diameter and surface energy values as displayed in Figure 3. On log axes, the relationship produces a straight line for the values considered, levelling off at bubble diameters over $1 \mathrm{~mm}$. Surface energy has an important influence but the bubble diameter is the parameter that determines the order of magnitude of the compression work required for unit foam volume.

$$
\frac{W_{C}}{V_{2}}=\frac{1}{\gamma-1} P_{2}\left(1-\left(\frac{P_{2}}{P_{1}}\right)^{\frac{1-\gamma}{\gamma}}\right)
$$




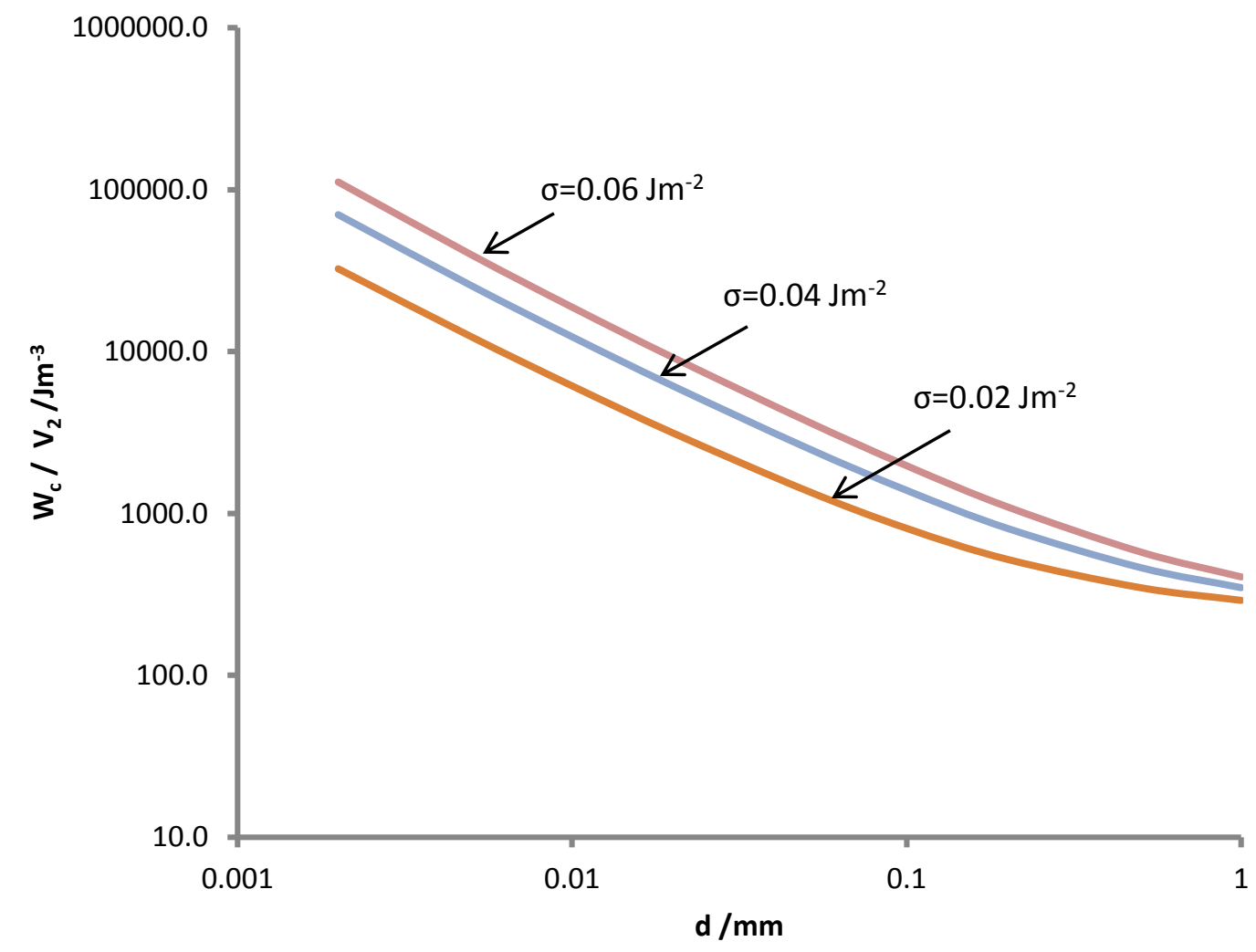

Figure 4. Log-log plot of the compression work as a function of bubble diameter for three representative values of surface energy.

To find the thermodynamic work to produce foam per unit ocean area, Equation 6 is multiplied by the volume fraction of air in the foam $x_{\text {air }}$. Equation 7 defines $x_{\text {air }}$ in terms of the densities of the foam $\left(\rho_{\text {foam }}\right)$, the aqueous solution $\left(\rho_{\text {sol }}\right)$ and air $\left(\rho_{\text {air }}\right)$. The volume of foam $\left(V_{\text {foam }}\right)$ per unit area of ocean is simply $h$. The volumetric fraction of air in the fully developed polyhedral foam varies according to how dry is the foam, a typical value of this parameter is around $95 \%$ and is used in subsequent calculations. 


$$
x_{\text {air }} \equiv \frac{V_{2}}{V_{\text {foam }}}=\frac{\rho_{\text {sol }}-\rho_{\text {foam }}}{\rho_{\text {sol }}-\rho_{\text {air }}}
$$

The energy per unit area of ocean needed to create the foam is obtained from equations 1,6 and 7 :

$$
\frac{W_{C}}{A_{o c}}=N \times d \times x_{\text {air }} \times \frac{1}{\gamma-1} P_{2}\left(1-\left(\frac{P_{2}}{P_{1}}\right)^{\frac{1-\gamma}{\gamma}}\right)
$$

For a foam capable of average reflectance of 0.5 over its life, putting values of $N=20$ and $x_{\text {air }}=0.95$, the energy required for the adiabatic compression of air entrapped in the foam is between 1.2 and 4.2 $\mathrm{J} \mathrm{m}^{-2}$ depending on surface energy and bubble diameter as plotted in Figure 5.

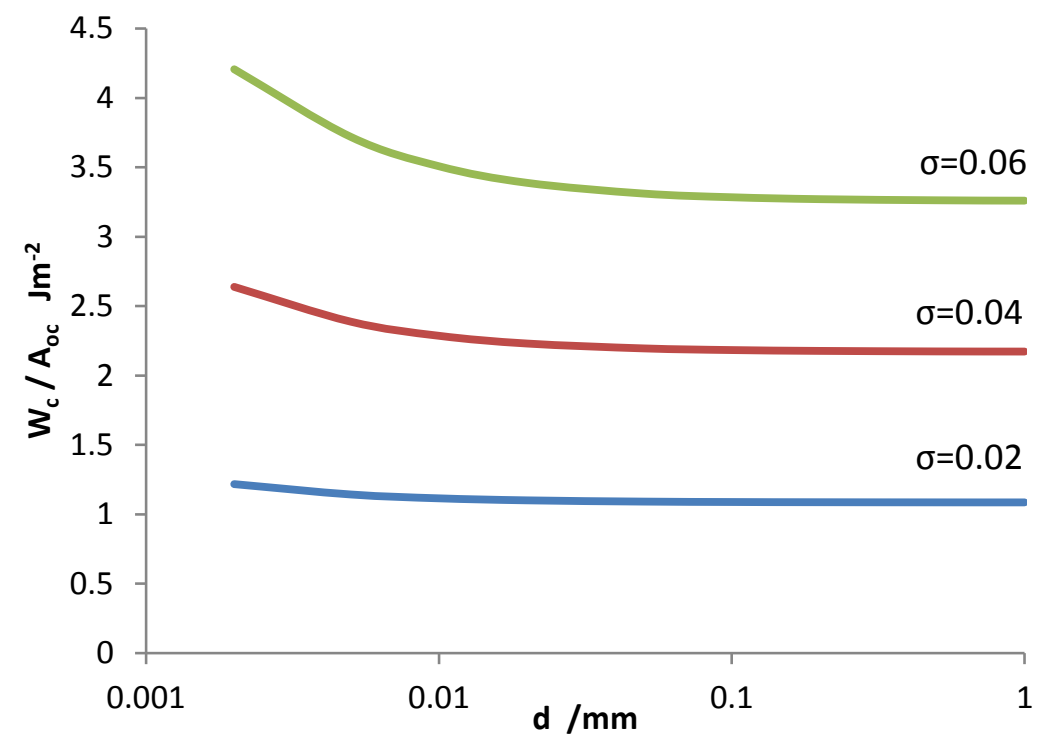

Figure 5. Compression work per unit area of ocean covered with foam as a function of bubble diameter.

The total energy required to produce foam with this reflectance in the surface of the ocean is estimated with Equation 3 and is between 2.8 and $9.5 \mathrm{~J} \mathrm{~m}^{-2}$ of ocean for a foam layer in which the path length of a ray passes 20 membranes. Its main influence is surface energy: the work of compression tends to level out with bubble diameter because as diameter increases, thus lowering $\mathrm{P}_{2} / \mathrm{P}_{1}$, volume of compressed gas increases if the number of layers is held constant (Figure 6). 


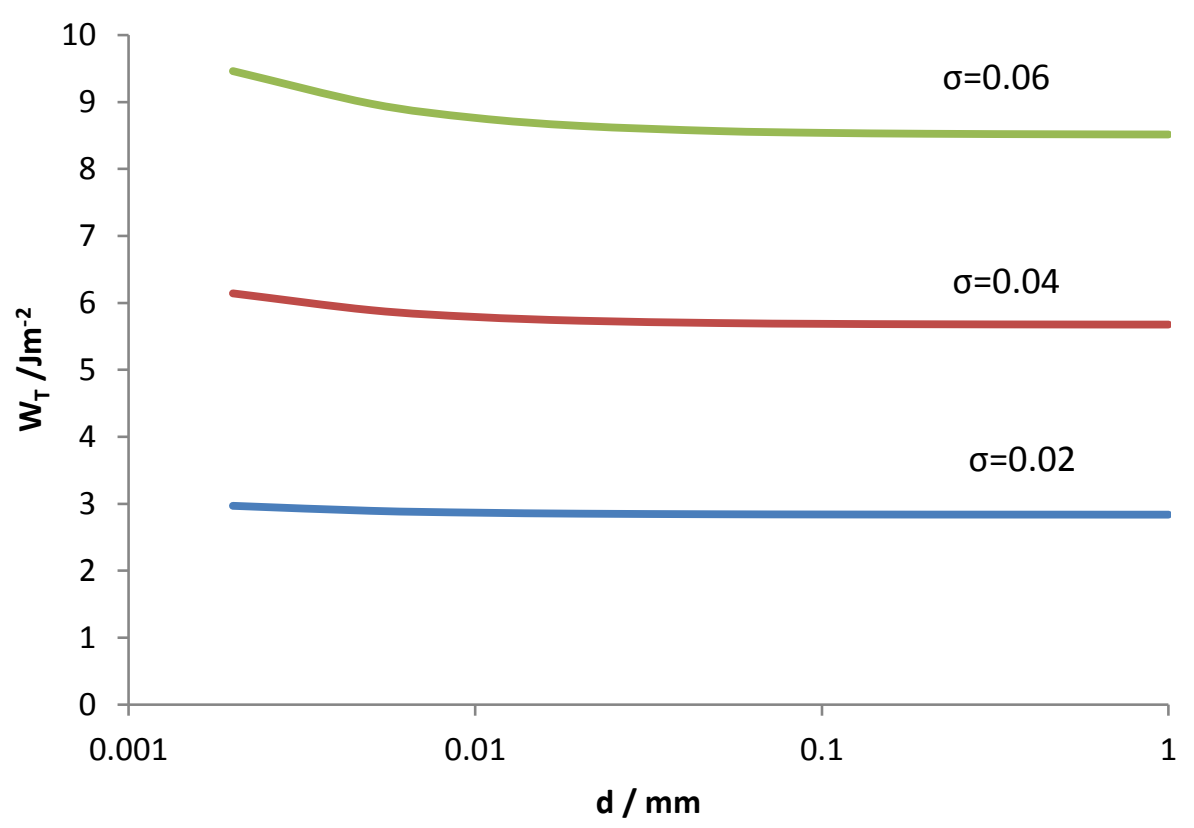

Figure 6. Total thermodynamic work $\left(\mathrm{W}_{\mathrm{T}}\right)$ to produce a 20 reflective layer foam per unit area of ocean as a function of bubble diameter.

\section{Power requirements}

Energy demands of $2.8-9.5 \mathrm{MJ} \mathrm{km}^{-2}$ at first seem prohibitive but what matters, since the energy is to be derived from wave, wind, solar or ship lubrication compressor power, is the capitalization of equipment needed to maintain the foam layer. This in turn depends on the average power requirement which clearly depend on the foam lifetime. Simply put, if the foam lasts for one month (2.6 Ms) the average power per $\mathrm{km}^{2}$ is $1-4 \mathrm{~W}$ for the energy demands given above. This is quite a modest demand.

In the steady state, foam would be produced at the same rate at which it is degraded. For a fixed power input, the ocean surface area covered in foam is proportional to the lifetime of the foam. This is shown schematically in Figure 7. This forms the basis of current research on ocean foams which aims to prolong their persistence in seawater. For seawater unmodified by surfactant addition, Callaghan et al. [40] express the area of whitecap, $A(t)$, at time, $t$, after formation by:

$$
A(t)=A_{0} \exp \left(-\frac{t}{\tau}\right)
$$

where $A_{0}$ is the maximum area after formation and $\tau$ is the whitecap foam decay time. While area decay follows this curve well, $\tau$ varies by a factor of 50 up to 10s. In the laboratory, seawater foams with added surfactants and gelling agents can survive for long periods and, if the upper surface dries, for several Ms. 


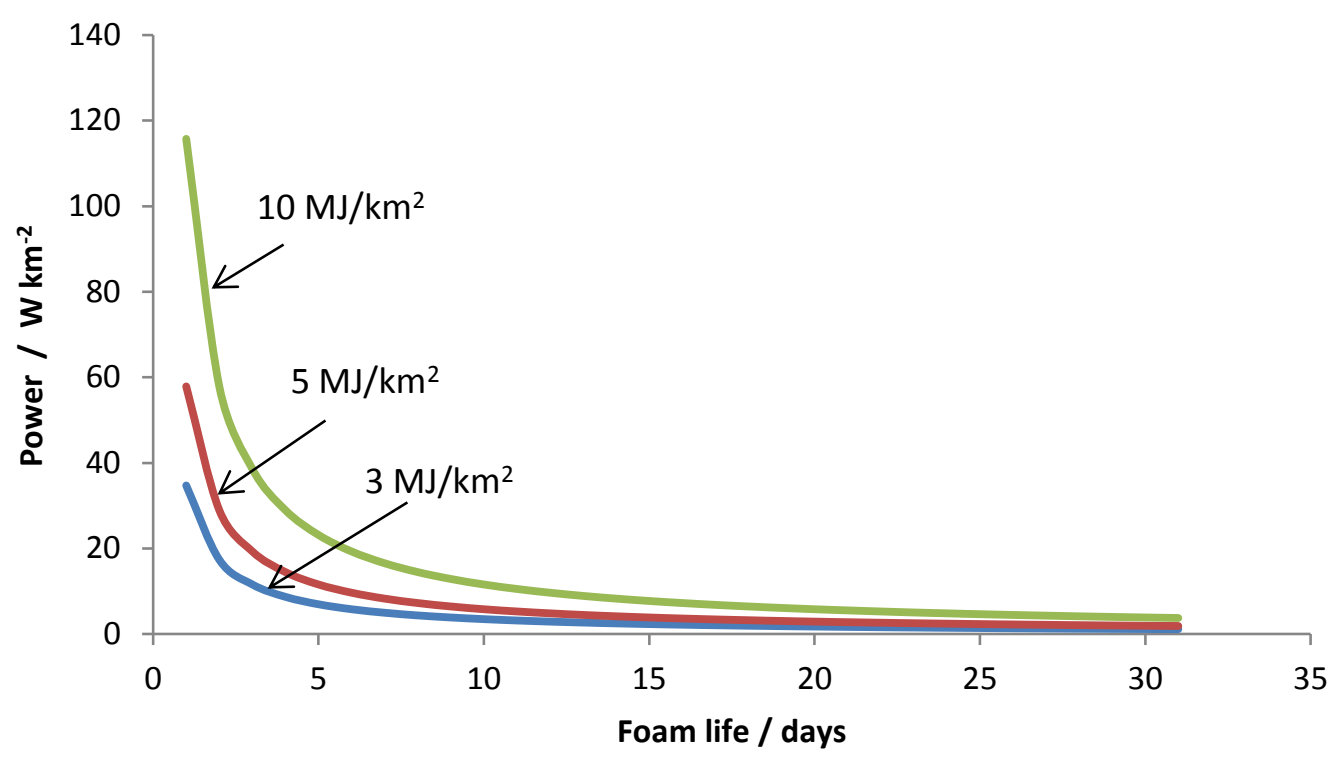

Figure 7. Power demand for the maintenance of $1 \mathrm{~km}^{2}$ ocean foam as a function of foam lifetime for three values of areal energy demand.

However Figure 7 does not address the transient at the initiation of the ocean mirror. In fact the duration of the transient is equal to the lifetime of the foam as shown in Figure 8. The total area of the foam that can be established at steady state is the area deposited per day multiplied by lifetime as also shown in Figure 8. The lifetime of the foam can instead be thought of as the time required regenerating the foam. The consumption of resources per unit time halves when the lifetime doubles.

$1 \mathrm{~km}^{2}$ per day added: lifetime 2 days

\begin{tabular}{|c|c|c|c|c|c|c|}
\hline $\begin{array}{l}\text { Day } \\
\text { no. }\end{array}$ & Foam & ersis & $n g t$ & end & the $c$ & \\
\hline 1 & $\mathrm{~F}$ & & & & & \\
\hline 2 & $\mathrm{~F}$ & $\mathrm{~F}$ & & & & \\
\hline 3 & D & $F$ & $F$ & & & \\
\hline 4 & $D$ & $\mathrm{D}$ & $F$ & $F$ & & \\
\hline 5 & $D$ & $\mathrm{D}$ & $D$ & $F$ & $\mathrm{~F}$ & \\
\hline 6 & D & $D$ & $D$ & D & $F$ & $F$ \\
\hline
\end{tabular}

$1 \mathrm{~km}^{2}$ per day added: lifetime 3 days

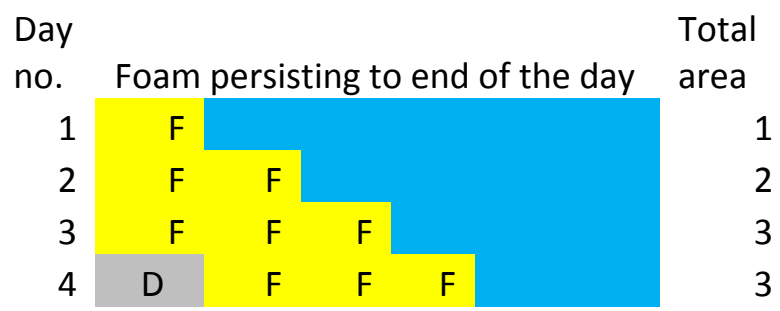




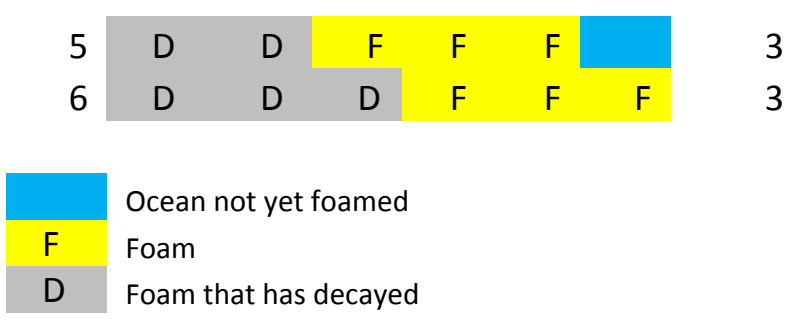

Figure 8. Foam placement and decay: the maximum area of foam is the product of the placed area and the lifetime.

Thus the amount of foam produced, and therefore the surface area it covers is proportional to the resources, $E$ used to produce and maintain the foam $E \propto A_{o c}$. Given a fixed resource, the area covered by foam is directly proportional to the lifetime, $T$, of the foam $A_{o c} \propto T$. For a given area covered in foam, the resources needed to produce and maintain it are inversely proportional to the lifetime of the foam , $E \propto \frac{1}{T}$.

The important characteristics of the foam, total size and lifetime are related to the rate of foam production $(\mathrm{dA} / \mathrm{dt})$ by:

$$
\frac{\mathrm{dA}}{\mathrm{dt}}=\frac{\mathrm{A}_{\mathrm{oc}}}{\mathrm{T}}
$$

In the steady state, the foam as a whole is sustained by producing the amount of foam that replaces that degraded with the passing of time. The power required to sustain the whole foam ( $\left.\mathrm{P}_{\text {foam }}\right)$ is calculated from:

$$
P_{\text {foam }}=\frac{d E}{d t}=\frac{d E}{d A} \times \frac{d A}{d t}=\frac{W}{A_{o c}} \times \frac{A_{o c}}{T}
$$

The power required to sustain the ocean mirror divided by the area of the ocean covered is a function of the variables shown in Table 2 in which the third column shows the way the power requirement depends on the parameter and the last column is the ratio of the highest and lowest typical values for the variables. Without efficiency factors, the power required per unit area of ocean covered varies from 4 to $120 \mathrm{~W} \mathrm{~km}^{-2}$ for the range of energy demands considered. It depends on the foam lifetime, surface energy and, at low diameters on bubble size but its values are relatively low indicating the viability of the intervention. Efficiency factors are not included yet and will significantly increase these numbers. 
Attention is centred on the energetic resources here but the materials requirements can be estimated quite easily based on surfactant addition levels of $1 \mathrm{wt} . \%[21,22]$. For $\mathrm{N}=20, \mathrm{x}_{\text {air }}=0.95$ and $1 \mathrm{~mm}$ bubble diameter, the volume of liquid in the foam per unit ocean area is $0.001 \mathrm{~m}^{3}$ which requires 10 g surfactant which could be metered into the compressed air stream as a masterbatch concentrate.

\begin{tabular}{|c|c|c|c|}
\hline Variable & Symbol & Relation with $\mathbf{P}_{\text {foam }} / \mathbf{A}_{\mathbf{o c}}$ & High-low ratio \\
\hline Bubble diameter & $\mathrm{d}$ & Constant above $\mathrm{d}=0.1 \mathrm{~mm}$ & 10,000 \\
\hline Surface energy & $\sigma$ & Almost linear & 6 \\
\hline Layers for reflection & $\mathrm{N}$ & Linear & $\sim 8$ \\
\hline $\begin{array}{c}\text { Foam-ocean reflectance } \\
\text { difference }\end{array}$ & $\Delta \mathrm{R}$ & Proportional & 2 \\
\hline Foam lifetime & $\mathrm{T}$ & Inversely proportional & 100 \\
\hline
\end{tabular}

Table 2. Relevant variables of the model developed to calculate the power needed to produce and sustain the ocean mirror.

\section{Estimation of foam area fraction}

The energy demand needs to be assessed in terms of the total area of the ocean covered by foam which in turn is related to the energy of the light reflected by the ocean mirror and hence the radiative forcing. The schematic of Earth's radiative budget that has become widely accepted is that in Figure 1.1 of Shepherd [26]. The average value of solar energy flux at the surface is $342 \mathrm{~W} \mathrm{~m}^{-2}$ of which $107 \mathrm{~W} \mathrm{~m}^{-2}$ or $31 \%$ leaves the Earth as short wavelength radiation without being incorporated into the climate system. Any increase in this outbound energy flux by climate protection efforts would counteract anthropogenic radiative forcing.

To counteract the effect of doubling $\mathrm{CO}_{2}$ concentration it would be necessary to change the earth's radiation balance by $4 \mathrm{Wm}^{-2}$ [26]. It is extremely unlikely that when the time comes to intervene with such global protection measures, a single strategy will be deployed. It is almost certain that risk will be mitigated by developing a portfolio of interventions which will include, in some form, most of the procedures currently under discussion. Furthermore, it is likely that a gradient of implementation will be planned, for example by converting merchant shipping with bubble generators in stages. However it is interesting to find out what fraction of ocean would need to be mirrored in order to deliver the full $4 \mathrm{Wm}^{-2}$.

This would be achieved by increasing planetary surface albedo from 0.15 to 0.17 . The albedo of the ocean is more homogeneous than land albedo and depends on solar zenith angle, wind speed, transmission by atmospheric cloud/aerosol and ocean chlorophyll concentration. The average ocean albedo is around 0.04 [41]. The ocean, $f_{o c}$, and land, $f_{\mathrm{T}}$, surface fractions are approximately $70 \%$ and 
$30 \%$ respectively. If $\mathrm{a}_{o c}$ and $a_{\mathrm{T}}$ are ocean and land albedos respectively, the planetary surface albedo is made up of:

$$
a=f_{o c} \mathrm{a}_{o c}+f_{\mathrm{T}} a_{\mathrm{T}}
$$

and the average land albedo, $a_{\mathrm{T}}$, is 0.41 , being more than 10 times the albedo of the ocean

If planetary surface albedo is to be raised to 0.17 as suggested [26], and land albedo does not change, ocean albedo will need to be increased to 0.067 to deliver the full $4 \mathrm{Wm}^{-2}$ and the area fraction of ocean that is foam with a reflectance $R_{N}$ is given by:

$$
f_{f}=\frac{a_{c}-0.04}{R_{N}-0.04}
$$

where $a_{c}$ is the target composite foam-ocean albedo (0.067 in this case). With $R_{N}=0.5$, the area fraction needed to do this is 0.059 . If the foam reflectance is 0.7 this falls to 0.041 . This estimate ignores many factors. It does not take into account regional variations in cloud cover and hence does not report top of atmosphere albedo. Crook et aI. [23] used an ocean-atmosphere coupled climate model to provide more precise estimates of ship-wake enhancement. They also reported regional climate consequences. The overlap of ship wakes which increases as more ships are converted and as foam life extends is also not considered. It is likely that while air injection for ship lubrication is continuous, the addition of surfactant can be interrupted. Nevertheless, these values represent enormous areas: the ocean surface area is $360 \times 10^{6} \mathrm{~km}^{-2}$. The lower fraction of 0.041 corresponds to the area of Antarctica. However, these values are based on the extreme case in which climate remediation relies entirely on an ocean mirror. This will not be the case for several reasons. Firstly, anthropogenic radiative forcing should not reach $4 \mathrm{Wm}^{-2}$ because global commitments have been made by the ratification of the Paris COP 21 agreement by most of the nations. Secondly, the risks associated with global protection by climate engineering are so great that it would be imprudent to rely on one type of intervention alone. The extent of the mirror should be as great as economically possible without compromising ecosystems, the environment or sustainable development. Thirdly, the input quantities are global averages; there is an average latitude at which these numbers are exact. The consequence of producing the foam closer to the equator from this average latitude would be more solar influx while the other parameters such as ocean albedo remain almost intact and so less area of foam is needed. It is not widely appreciated that the deployment of the ocean mirror should take place as close as possible to the equator in order to reduce the area of foam required. The effect on changes to precipitation, especially between northern and southern hemispheres, depends on the geographical distribution of foam. In this context, foam deployment from merchant ships alluded to above, would require adjustment of traffic routes which are presently northern-hemisphere 
dominated. Quite novel contractual arrangements between governments and shipping lines would be needed!

An idea of the area that could reasonably be administered can be gained from deployment of bubble generators fitted to merchant ships such as the Mitsubishi system [30] but modified to deliver a persistent foam. This is the technology modelled by Crook et al. [23] which shows that its effects on precipitation and ocean primary productivity are no worse than those incurred by climate change. Suppose that of the 50,000 merchant ships worldwide, 35,000 are at sea at any time and their average speed is $11 \mathrm{~ms}^{-1}$ (22 knots) and that the wake width is $75 \mathrm{~m}$. (Reference 23 suggests $50-100 \mathrm{~m}$ ). Then the ocean area foamed per 24 hours is $2.5 \times 10^{6} \mathrm{~km}^{2}$ before including efficiency factors, sea roughness factor, ship-wake overlap and variations in cloud cover (which affects the extent of climate forcing) and so the minimum persistence of foam is 8.5 days for the full $21.2 \times 10^{6} \mathrm{~km}^{2}$ (0.059 of ocean) needed to offset the $4 \mathrm{Wm}^{-2}$ needed to compensate for doubling of $\mathrm{CO}_{2}$.

\begin{tabular}{lll}
\multicolumn{2}{c}{ Ocean mirror } \\
Effectiveness & $\begin{array}{l}\text { Strongly depends on the scale of implementation and } \\
\text { geographical location. }\end{array}$ & Low - High \\
\hline Affordability & $\begin{array}{l}\text { Power requirements are low as estimated in this paper. } \\
\text { Deployment through merchant ships offers reduced costs. }\end{array}$ \\
\hline Timeliness & $\begin{array}{l}\text { Could be readily implemented in merchant ships or as an } \\
\text { independent project. Albedo is increased immediately. }\end{array}$ & High \\
\hline Safety & $\begin{array}{l}\text { Energy and materials should be sourced in-situ not } \\
\text { interfering with marine ecosystems. } \\
\text { Climate implications are being studied (Crook et al. 2016) }\end{array}$ & Medium \\
\hline
\end{tabular}

Table 3. The ocean mirror as assessed in the manner of the Royal Society report "Geoengineering the climate" [26].

Table 3 summarizes the feasibility of the ocean mirror using the four criteria of the Royal Society's report [26] and the same style of presentation. That report preceded the appearance of formal suggestions in the literature that the reflectance of bubbles could be used as a climate intervention and so it does not include the option. Nevertheless, seven years later, there has still been insufficient research in global protection measures to warrant decisions to proceed or on which options with which to proceed. This neglect raises the spectre that precipitate decisions might be taken cum pavore in a context of widespread suffering without the necessary understanding of the consequences and the associated dangers.

\section{Summary and conclusions}


The energy demand to produce an ocean mirror using foam is assessed in terms of the work of compression and the liquid-vapour surface area created. Although the energy is high: $2.5 \mathrm{MJ} \mathrm{km}^{-2}$ for bubble diameters from $0.1-1 \mathrm{~mm}$ and intermediate surface energy of $0.04 \mathrm{~J} \mathrm{~m}^{-2}$, the power demand to maintain foam cover is inversely related to foam lifetime. Thus if the foam lasts 5 days, the minimum power demand is $12 \mathrm{~W} \mathrm{~km}^{-2}$. The conclusions indicate that attempts to obtain persistent foams in seawater preferably using ingenerate resources should be given priority. It is shown that before including efficiency factors, the large areas of reflective ocean needed to compensate for a doubling of $\mathrm{CO}_{2}(6 \%$ of ocean) are attainable by fitting bubble lubrication to the existing world fleet of merchant ships with surfactant additions, provided a minimum persistence of 8.5 days can be achieved. However this is very unlikely to be needed: regulatory measures and risk mitigation by using a portfolio of global protection procedures will reduce this areal demand. Positioning of the ocean mirror at low latitudes will obviously reduce the ocean area needed but the more local is the deployment, the less uniform may be the effect on temperature and precipitation.

\section{Acknowledgement}

EGO was supported by the Mexican National Council for Science and Technology (CONACyT) scholarship scheme.

\section{References}

[1] Costello, A. and 27 others, 2009. Managing the health effects of climate change, Lancet. 373:1693-1733.

[2] Watts, N. and 44 others, 2015. Health and Climate change: policy responses to protect public health, Lancet. 386: 1861- 1914.

[3] Sullivan, G.R., 2007. National security and the threat of climate change, CNA Corpn. Virginia, USA.

[4] O’Sullivan, T.M., Ramsay, J., 2015. Defining and Distinguishing Homeland from National Security and Climate-Related Environmental Security, in Theory and Practice. Journal of Homeland Security and Emergency Management, 12: 43-66.

[5] Hsiang S.M., Burke, M., 2014. Climate, conflict, and social stability: what does the evidence say? Climatic Change, 123:39-55.

[6] Moreno-Cruz, J.B., Keith, D.W. 2013. Climate policy under uncertainty: a case for solar geoengineering, Climatic Change, 121: 431-444.

[7] Scheer, D., Renn O., 2014. Public Perception of geoengineering and its consequences for public debate, Climatic Change 125: 305-318. 
[8] Corner, A., Parkhill, K., Pidgeon, N., Vaughan, N.E., 2013. Messing with nature? Exploring public perceptions of geoengineering, in the UK, Global Environmental Change, 23: 938-947.

[9] Keith, D.W., 2000, Geoengineering the Climate: history and Prospect, Annual Reviews Energy and Environment, 25: 245-284.

[10] Rodhe, H., Charlson, R., Crawford, E., 1997, Svante Arrhenius and the greenhouse effect, Ambio, 26: 2-5.

[11] Budyko, M.I., 1977. Climate Changes. American Geophysical Union, Washington DC, English translation of 1974 Russian volume p. 244.

[12] Crutzen, P., 2006.Albedo enhancement by stratospheric sulphur injections: a contribution to resolve a policy dilemma? Climatic Change, 77: 211-219.

[13] Evans, J.R.G., Stride, E.P.J., Edirisinghe, M.J., Andrews, D.J., Simons, R., 2010. Can oceanic foams limit global warming? Climate Research, 42:155-160.

[14] Seitz, R., 2011. Bright water: hydrosols, water conservation and climate change. Climatic Change 105: 365-381.

[15] Whitlock, C.H., Bartlett, D.S., Gurganus, E.A., 1982. Sea foam reflectance and influence on optimum wavelength for remote sensing of ocean aerosols. Geophysical Research Letters, 9: 719-722.

[16] Stabeno, P.J., Monahan, E.C., 1986. The influence of whitecaps on the albedo of the sea surface, in Oceanic Whitecaps, D.Reidel Publ. Co. pp. 261-266.

[17] Devetzoglou, M.A., Evans, J. R.G., 2014. Diffuse reflectance of foams, Journal of Marine Research, 72: 19-29.

[18] Andreas, E.L., Monahan, E.C., 2000. The role of whitecap bubbles in air-sea heat and moisture exchange. Journal of Physical Oceanography, 30: 433-442.

[19] Gatebe, C.K., Wilcox, E., Poudyal, R., Wang, J., 2011. Effect of ship wakes on ocean brightness and radiative forcing over the ocean, Geophysical Research Letters, 38: L17702.

[20] Zhang, X., Lewis, M., Bissett, W.P., Johnson, B. Kohler, D., 2004. Optical influence of ship wakes, Applied Optics, 43: 3112-3132.

[21] Aziz, A., Hailes, H.C., Ward, J., Evans, J.R.G., 2014. Long-term stabilization of reflective foams in sea water, RSC Advances, 4: 53028-53036.

[22] Rowland, T., Hailes, H.C., Evans, J.R.G., 2015. Sea salt as a potential ocean mirror material, RSC Advances, 5: 38926-38930.

[23] Crook, J.A., Jackson, L.S., Forster, P. M., 2016. Can increasing albedo of existing ship wakes reduce climate change? Journal of Geophysical research: Atmospheres, 121: 1549-1558. 
[24] Cvijanovic, I., Caldeira, K., MacMartin, D.G., 2015. Impacts of ocean albedo alteration on Arctic sea ice restoration and Northern Hemisphere climate, Environmental Research Letters, 10: 044020 .

[25] Gordon, H.R., Jacobs, M.M., 1977. Albedo of the ocean-atmospheric system: influence of sea foam, Applied Optics, 16: 2257-2260.

[26] Shepherd, J. 2009. Geoengineering the Climate: science governance and uncertainty, The Royal Society London, Policy document 10/09.

[27] McNutt, M.C. (Chair), 2015.Climate Intervention: Reflecting Sunlight to Cool Earth, National Academies Press, Washington DC, pp.128-130.

[28] Salter, M. E., Upstill-Goddard, R.C., Nightingale, P.D., Archer, S.D., Blomquist, B., Ho, D. T., Huebert, B., Schlosser, P., Yang, M., 2011. Impact of an artificial surfactant release on air-sea gas fluxes during Deep Ocean Gas Exchange Experiment II, Journal of Geophysical Research, 116: C11016.

[29] Polovina, J.J., Howell, E.A., Abecassis, M., 2008. Ocean's least productive waters are expanding, Geophysical Research Letters, 35, Art. No. L03618.

[30] Mäkiharju, S.A., Perlin, M., Ceccio, S.L. 2012. On the energy economics of air lubrication drag reduction, International Journal of Naval Architecture and Ocean Engineering, 4: 412-422.

[31] Johnson, B.D., Cooke, R.C., 1981. Generation of Stabilized Microbubbles in Seawater, Science, 213: 209-211.

[32] Johnson, B.D., Cooke, R.C., 1980. Organic Particle and Aggregate Formation Resulting from the Dissolution of Bubbles in Seawater, Limnology and Oceanography, 25: 653-661.

[33] Weaire, D., Phelan, R., 1994. A counter example to Kelvin's conjecture on minimal surfaces. Philosophical Magazine Letters, 69: 107-110.

[34] Gabbrielli, R., 2009. A new counter-example to Kelvin's conjecture on minimal surfaces. Philosophical Magazine Letters, 89, 483-491.

[35] Chalkley, D.T., 1953. The tetrakaidecahedron as the basis for the computation of cell volume and density, Science, 118: 599-600.

[36] Eaves, D., 2004. Handbook of Polymer Foams, iSmithers RAPRA Publishers, Shrewsbury, UK, p.2.

[37] Pabst, W., Gregorová, E., 2007. Characterization of particles and particle systems, FRVŠ 674 / 2007 F1 / b ICT Prague, p.96.

[38] Nguyen, A.V., Schulze, H.J., Colloidal Science of Flotation, Surfactant Science Series, Vol. 118,2004, p.661

[39] Nayar, K. G., Panchanathan, D., McKinley, G. H., Lienhard, J. H., 2014. Surface tension of seawater. Journal of Physical and Chemical Reference Data, 43: 043103. 
[40] Callaghan, A.H., Deane, G.B., Stokes, M. D., Ward, B., 2012. Observed variation in the decay time of oceanic whitecap foam, Journal of Geophysical Research, 117: C09015.

[41] Payne, R. E., 1972. Albedo of the sea surface. Journal of the Atmospheric Sciences, 29: 959970. 